\title{
A Short Review on Biological Potential Thiopyridazine Analogues
}

\section{Mohammad Asif*}

Department of Pharmacy, GRD (PG) Institute of Management and Technology, Dehradun, Uttarakhand-248 009, India

\begin{abstract}
Pyridazinone/thiopyridazinone derivatives represent one of the most active classes of compounds possessing a wide spectrum of biological activities such as cardiovascular properties, anti-inflammatory, analgesic, antidiabetic, antiviral, anticancer, antimicrobial, anticonvulsant and other biological activities. Some pyridazinthiones were tested for biological activities. Various pyridazinone/thiopyridazine derivatives were exhibited anticonvulsant activity against maximal electroshock seizure test, various pyridazine-thione derivatives were exhibited antitumor activity and some thiopyridazines were exhibited anti-microbial activity against various strains like Staphylococcus aureus, Escherichia coli, Bacillus subtillis and Candida albicans. Tricyclic ring system, pyridazino[6,1-b]quinazolin10-ones, benzimidazolo-pyridazine thione, and 1,2,4-benzotriazino-pyridazinethione along with imidazo-[1,2-b]pyridazinethione, 1,2,4-triazolo[4,3-b] pyridazine-thione derivatives were exhibited antimicrobial activity against gram-positive and gram negative bacteria as well as fungi.
\end{abstract}

Keywords: Pyridazinones; Anticonvulsant; Pyridazin-3-thiones; Antimicrobial; Antitumor

\section{Introduction}

The review was carried out to discuss in detail about the substituted pyridazinone compounds. Heterocyclic compounds have been successfully used as antimicrobial, anticancer, antipyretic, hypoglycemic, antihypertensive, anti-tubercular, anti-inflammatory, analgesic, anti-viral and other useful agents. Various organo-sulfur compounds present in living and nonliving things. They occur in open chain, alicyclic, aromatic and heterocyclic compounds containing sulfur atoms or atoms as a part of chain/ring in the structure. In this review briefly study about the structure features and biological interest of thio-pyridazine derivatives and concluded that many researches had tested on thio-pyridazine derivatives having the biological activities. The chemistry of pyridazines and their fused heterocyclic derivatives has received considerable attention owing to their effective biological importance. Pyridazines have been reported to possess antimicrobial [1-3], antituberculosis [4-6], antifungal [7], anticancer [8], antihypertensive [9], herbicidal [10], anti-inflammatory [11] activities, and protein tyrosine phosphatase $1 \mathrm{~B}$ inhibitors [12]. They also have an immense potential in agricultural science as plant growth regulators and crop protection agents [13]. The incorporation of two moieties increases biological activity of both and thus it was of value to synthesize new heterocyclic compounds having two moieties in the same molecules. Various derivatives of pyridazine incorporating other heterocyclic rings have been shown to display a wide spectrum in biological and therapeutic areas [14-18].

\section{Biological Activities}

Various pyridazine derivatives have received considerable attention due to their wide range applications. Pyridazines are reported to exhibit antibacterial, antifungal, antituberculosis, antinociceptive, anthelmintic, antidiabetic activities and also as human rhinovirus (HRV-3) inhibitors activities. The 6-chloropyridazin-3(2H)-thione (1) for the synthesis of pyridazines to tested for their antimicrobial activities [19,20]. The 6-Chloropyridazin-3(2H)-thione (1) were used as a starting material for the synthesis of some heterocyclic compounds. Compound (1) reacts with bifunctional nucleophile like anthranilic acid, 2-aminophenol, and 2-chlorophenylhydrazine to give a tricyclic system as 2-thioxo-1,2,10-trihydropyridazino[6,1-b] quinazolin-10-ones (2a-c), benzimidazolopyridazine thione (3), and 1,2,4-benzotriazinopyridazinethione (4) derivatives. Imidazo [1,2-b] pyridazine-thione derivative (5) was prepared by reaction of compound (1) with phenylalanine. Other compounds were also synthesized such as 1,2,4-triazolo [4,3-b] pyridazinethione derivatives (6), (7a, b), (8a, b) and compound (9). Stirring a solution of pyridazine-3thione (1) and 2,4-dinitrobenzenesulfenyl chloride in acetic acid give 2,4-dinitrophenyl-6-chloropyridazyldisulfide (10).

The antimicrobial activities of these compounds have been tested against Staphylococcus aureus, Bacillus subtilis, Pseudomonas aurignosa, and Echerichia coli and antifungal activity against Candida albicans, Aspergillus niger, at a concentration of $500 \mu \mathrm{g} / \mathrm{mL}$ in DMF. Ampicillin and mycostatin, at a concentration $500 \mu \mathrm{g} / \mathrm{mL}$, were used as reference drug against bacteria and fungi, respectively. Compounds (2a), (4) and (9) possess high activity, while compounds (3), (6), (8b), and Bis (6-chloropyridazyl) disulfide (11) possess moderate activity against gram positive strains. As far as gram-negative microbes are concerned, compounds (2a), (9), and (11) showed high activity while compounds (3), (7a), and (12) display moderate activity. Compounds (9) and phenyl pyridazylthione disulfide (12) also exerted high activity while compounds (2a), (3), (4), and (8b) have moderate activity against fungi [21]. Some of these compounds possess a highly response against grampositive and gram-negative bacteria as well as fungi (Figure 1).

Pyridazine-thione (14) was used as a key intermediate for the preparation of numerous pyridazine derivatives such as 3,3'-(6,6-bis $(3,4-$ dimethylphenyl)-3,3'-bipyridazine-4,4'-diyl)-bis(2-phenyl-1H-indole) (15), 1,2-bis(6-(3,4-dimethylphenyl)-4-(2-phenyl-1H-indol-3-yl) pyridazin-3-yl) disulfane (16), 2-(3,4-dimethylphenyl)-4-(2-phenyl1H-indol-3-yl)-10H-pyridazino[6,1-b]quinazolin-10-one (17a), 8-bromo-2-(3,4-dimethylphenyl)-4-(2-phenyl-1H-indol-3-yl)-10Hpyridazin[6,1-b]quinazolin-10-one (17b), 3-(6-(3,4-dimethylphenyl)4-(2-phenyl-1H-indol-3-yl)-pyridazin-3(2H)-ylidene)pentane-2,4-

*Corresponding author: Mohammad Asif, Assistant Professor, Department of Pharmacy, GRD (PG) Institute of Management and Technology, Dehradun, Uttarakhand-248 009, India, Tel: 9897088910; E-mail: aasif321@gmail.com

Received August 05, 2018; Accepted August 10, 2018; Published September 17,2018

Citation: Asif M (2018) A Short Review on Biological Potential Thiopyridazine Analogues. Med Chem (Los Angeles) 8: 259-264. doi: 10.4172/2161-0444.1000522

Copyright: (c) 2018 Asif M. This is an open-access article distributed under the terms of the Creative Commons Attribution License, which permits unrestricted use, distribution, and reproduction in any medium, provided the original author and source are credited. 


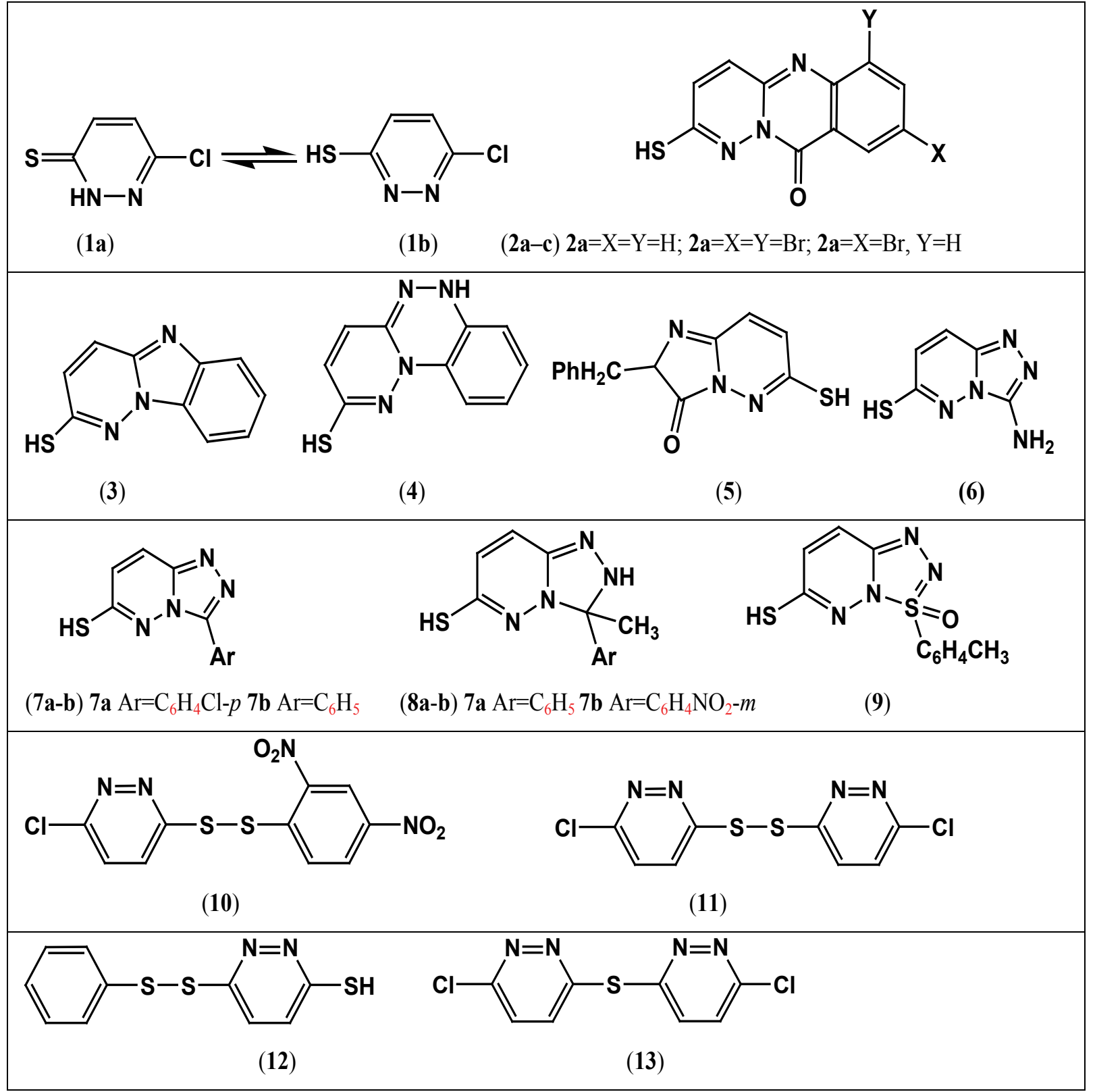

Figure 1: The 6-chloropyridazin-3(2H)-thione for the synthesis of pyridazines to tested for their antimicrobial activities.

dione (18), 3-(3-(3,5-dimethyl-4H-pyrazol-4-ylidene)-6-(3,4-dimethylphenyl)-2,3-dihydro-pyridazin-4-yl)-2-phenyl-1H-indole

3-(6-(3,4-dimethyl-phenyl)-4-(2-phenyl-1H-indol-3-yl)pyridazin-3ylthio)-1,3-diphenyl-propan-1-one (20), 3-(6-(3,4-dimethylphenyl)-3-(3hydrazono-1,3-diphenylpropylthio) pyridazin-4-yl)-2-phenyl-1H-indole (21), 1-(6-(3,4-dimethylphenyl)-4-(2-phenyl-1H-indol-3-yl) pyridazin3-yl) thiourea (22), 1-acetyl-3-(6-(3,4-dimethylphenyl)-4-(2-phenyl-1Hindol-3-yl)pyridazin-3-yl)-2-thioxodi hydro-pyrimidine-4-,6- $(1 \mathrm{H}, 5 \mathrm{H})$ dione (23), Ethyl 2-(6-(3,4-dimethylphenyl)-4-(2-phenyl-1H-indol-3-yl) pyridazin-3-ylthio) acetate (24), 2-(6-(3,4-dimethylphenyl-4-(2-phenyl$1 \mathrm{H}$-indol-3-yl) pyridazin-3-ylthio)-N-(naphthalen-1-yl) acetamide (25), 3-(6-(3,4-dimethylphenyl)-3-(methylthio) pyridazin-4-yl)-2-phenyl1H-indole (26), 2-(6-(3,4-dimethylphenyl)-4-(2-phenyl-1H-indol-3-yl) pyridazin-3-ylthio) acetohydrazide (27), 5-(6-(3,4-dimethyl phenyl)-4-
(2-phenyl-1H-indol-3-yl) pyridazin-3-ylthio)methyl)-1,3,4-oxadiazole2(3H)-thione (28), 4-(6-(3,4-dimethylphenyl)-4-(2-phenyl-1H-indol-3yl)pyridazin-3-ylthio)-5-(2-hydroxy-phenyl)-1,2-dihydro-3-H-pyrazol-3one (29), N-benzyl -6-(3,4-dimethylphenyl)-4- (2-phenyl-1H-indol-3-yl) pyridazine-3-amine (30a), 6-(3,4-dimethylphenyl)-4-(2-phenyl-1H-indol3-yl)-N-(pyridin-2-yl) pyridazin-3-amine (30b). A series of pyridazines containing the 2-phenylindole at 4-position hoping to improve the antitumor activity of the compounds. Potential cytotoxicity of compounds $(17 \mathrm{a}, 17 \mathrm{~b}, 18,20,26,30 \mathrm{a}$ and 30b) were tested against MCF7 (breast carcinoma cell line), HEPG2 (hepatocellular carcinoma cell line), HCT 116 (colon carcinoma cell line) line [22] (Figure 2).

Cytotoxicity against different human cancer cell lines in vitro for test of anti-tumor cytotoxicity of compounds $17 \mathbf{a}, \mathbf{1 7} \mathbf{b}, \mathbf{1 8}, \mathbf{2 0}, \mathbf{2 6}$, 
<smiles>[R]c1ccc2nc3c(Br)cc(Br)nn3c(=O)c2c1</smiles>

(4a-b) $a: R=H b: R=B r$<smiles>CC(=O)C(C(C)=O)=C1NN=C(Br)C=C1Br</smiles>

(5)<smiles>[Al]c1cc(Cl)nnc1SSc1nnc(Cl)cc1Br</smiles>

(3)
(7)<smiles>O=C(CC(SC1NN=C(Br)C=C1Br)c1ccccc1)OCc1ccccc1</smiles><smiles>CC1=NN=C(C)C1=C1NN=C(Br)C=C1[Ga]</smiles>

(6)<smiles>CCOC(=O)CNc1nnc(Br)cc1Br</smiles>

(9)

(10)<smiles>CSc1nnc(Br)cc1Br</smiles>

(12)
(13)<smiles>NNC(=O)CSc1nnc(Br)cc1Br</smiles>

(14)<smiles>[Al]c1cc(Br)c(SCc2n[nH]c(=S)o2)nn1</smiles>

(15)<smiles>CCc1cc(Br)c(Sc2cc(O)n[nH]2)nn1</smiles>

(16) $\mathrm{Ar} r^{\prime}=\mathrm{H} \mathrm{Ar}=3,4\left(\mathrm{CH}_{3}\right)_{2} \mathrm{C}_{6} \mathrm{H}_{5}$

$17 \mathrm{aAr}=$<smiles></smiles>

$17 \mathrm{bAr}{ }^{\prime \prime}=$<smiles>Cc1ccccc1O</smiles>

Figure 2: A series of pyridazines containing the 2-phenylindole at 4-position to improve the antitumor activity of the compounds. Potential cytotoxicity of compounds was tested against MCF7, HEPG2, HCT 116. 


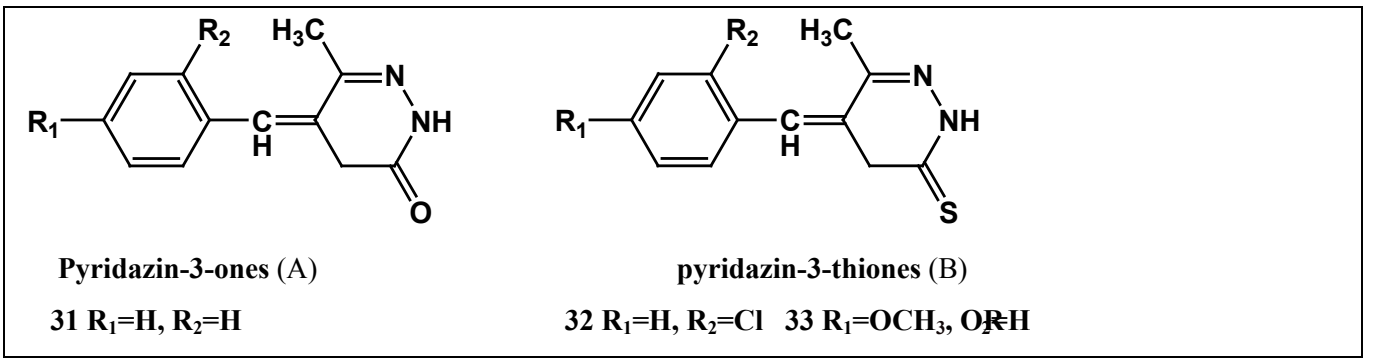

Figure 3: pyridazin-3-thione were tested for antibacterial activity against certain pathogenic bacteria by disc diffusion method.

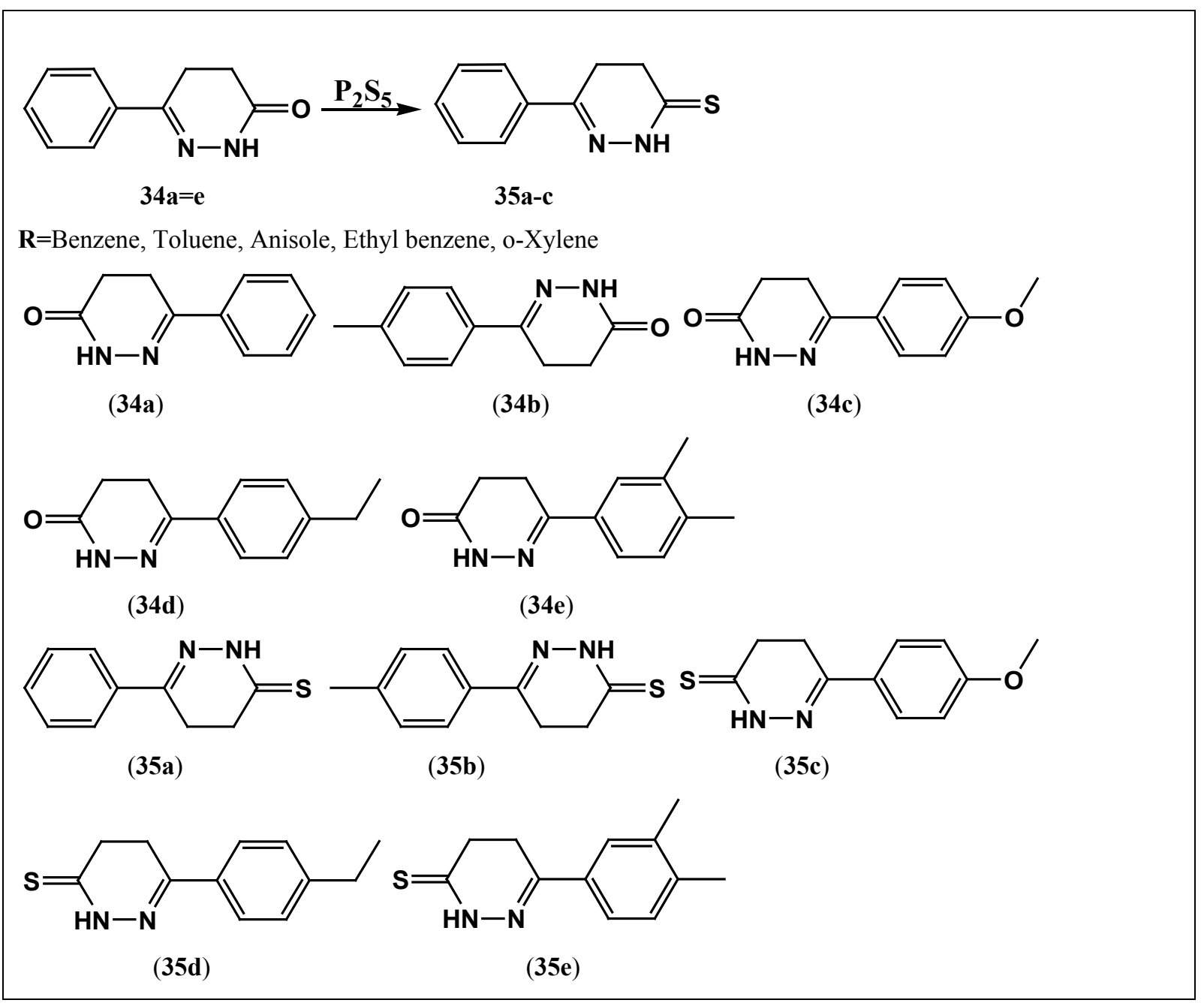

Figure 4: 6-aryl-2,3,4,5-tetrahydro-3-pyridazinones and 6-aryl-2,3,4,5-tetrahydro-3-thio-pyridazinones were tested for their anticonvulsant activity.

30a and 30b, three different human cancer cell lines were used: MCF7 (breast carcinoma cell line), HEPG2 (hepatocellular carcinoma cell line), HCT116 (colon carcinoma cell line) cytotoxicity. The survival fractions were gradually decreased as the concentration of the tested compounds was increased. It shown that 18, 20, 26, 30a and 30b are the compounds of lowest $\mathrm{IC}_{50}$ which means that they are the most effective cytotoxic drugs, accordingly compounds $26,30 \mathrm{a}$ and $30 \mathrm{~b}$ can be used as very potent cytotoxic drug for colon carcinoma cell, while $\mathbf{1 8}$ and $\mathbf{2 0}$ as moderate cytotoxic drug for colon and liver carcinoma cell respectively, while the remaining compounds are very weak cytotoxic drug. A series of $17 \mathbf{a}, 17 \mathbf{b}, 18,20,26,30 a$ and $30 b$ compounds have different anti-tumor effects and $\mathrm{IC}_{50}$ values of them were discussed. Compounds 26, 30a and 30b can be used as very potent cytotoxic drug for colon carcinoma cell, while $\mathbf{1 8}$ and $\mathbf{2 0}$ as moderate cytotoxic drug for colon and liver carcinoma cell respectively, while the remaining compounds are very weak cytotoxic drug [22].

The action of phosphorus pentasulfide on the lactam function of pyridazin-3-ones, allowed us to obtain pyridazin-3-thiones, by reacting the sulfur atom with several reagents (alkyl halide, hydrazine 
hydrate) [23-25]. The action of pentasulfide on ketones led to the thione function $[26,27]$. Thus the reaction conducted at reflux in pyridine on pyridazin-3-ones for 4 hours lead to pyridazin-3-thiones in good yields. The acute toxicity study showed that the synthesized derivatives are tolerated. Indeed, the limit dose of $1500 \mathrm{mg} / \mathrm{kg}$ i.p caused no lethality until 14 days. No effect was observed on groups of mice after oral administration at escalating doses. We deduce that the lethal dose 50 $\left(\mathrm{LD}_{50}\right)$ is probably more than $1500 \mathrm{mg} / \mathrm{kg}$. The synthesized compounds 5(1'-benzylidène)-6-méthyl-(2H)-pyridazin-3-thione, 5(2'-chloro1'-benzylidène)-6-méthyl-(2H)-pyridazin-3-thione, 5(4'méthoxy-1'benzylidène)-6-méthyl-(2H)-pyridazin-3-thione (31-33) were tested for antibacterial activity against certain pathogenic bacteria by disc diffusion method using both gram positive S. aureus, B. subtillis, gram negative $E$. coli and antifungal activity against $C$. albicans. Thus only the derivative 32 showed significant activity against $S$. aureus and E. coli. The presence of an electron attractor groups on the aromatic ring as chloro group is favorable for that activity. The derivative $\mathbf{3 3}$ containing the aromatic ring substituted by an electron donor by mesomeric effect $\left(-\mathrm{OCH}_{3}\right)$ inhibit the activity. In the case of $\mathrm{C}$. albicans chloro group is not necessary, since the derivatives $\mathbf{3 1}$ and $\mathbf{3 2}$ have similar activity, however the $\left(-\mathrm{OCH}_{3}\right)$ group inhibits the activity. In conclusion, among the derivatives synthesized product $\mathbf{3 2}$ has a significant antimicrobial activity; in addition the acute toxicity study showed that this derivative has a low toxicity with a lethal dose 50 elevated [28] (Figure 3).

Various researches indicated that the presence of at least one aryl group, one or two electron donor atoms and/or an $\mathrm{NH}$ group in a special spatial arrangement is essential for antiepileptic activity. The presence of at least one aryl group, one or two electron donor atoms and/or an $\mathrm{NH}$ group in a special spatial arrangement seems to be necessary for antiepileptic activity. A study of anticonvulsant agents reveals that the presence of an amide moiety, cyclic or not, is present in most antiepileptic's. The pyridazinone ring system agrees with this salient feature and many papers have reported antiepileptic activities of pyridazine derivatives. Hence this feature of the ring system was tapped for the presence of any anticonvulsant activity [29,30]. A series of substituted 6-aryl-2,3,4,5-tetrahydro-3-pyridazinones (34a-e) and 6-aryl-2,3,4,5-tetrahydro-3-thio-pyridazinones (35a-e) were tested for their anticonvulsant activity. The substituted 6-aryl-tetrahydro-3pyridazonone (34a-e) followed by substitution with sulphur to yield the compounds (35a-35e). All the compounds 34a-e and 35a-e were tested for anticonvulsant activity by maximal electroshock-induced seizure (MES) test. The starting dose of the test compound was 10, 25, 50 and $100 \mathrm{mg} / \mathrm{Kg}$ and standard drug Phenytoin $25 \mathrm{mg} / \mathrm{Kg}$. some compounds showed significant activity, rest compound were showed moderate anticonvulsant activity [31] (Figure 4).

\section{Discussion}

Because of the diversity in synthetic procedures, physiological and industrial significance, hetero cyclic chemistry has been and continues to be one of the most active areas of organic chemistry. As a result numerous heterocyclic compounds have been successfully used as antibacterial, anticancer, antipyretic, hypoglycemic, antihypertensive, antitubercular, anti-inflammatory and anti-HIV agents. In addition, they have also been used in agriculture, plastics, polymers, dyes and textiles. Hence heterocyclic chemistry still continues to draw the attention of synthetic organic chemists and is of great scientific interest. All large number of organo-sulfur compounds occur in living and non-living object. Organo-sulfur compounds lead to the fact that some of the compounds are useful in scientific and industrial growth. During the last three decades organo-sulfur chemistry developed at a much faster pace than any other branches of organic chemistry. The pyridazin derivatives are known for their therapeutic potential such as antihypertensive and cardio tonic, antifungal and other properties are also reported [32-35]. Pyridazines containing the group sulfur have important pharmacological activities.

\section{Conclusion}

Hetero cyclic chemistry has been and continues to be one of the most active areas of organic chemistry. As a result thio-pyridazine compounds have been successfully used as antibacterial, anticancer, anticonvulsant agents. Hence thio-pyridazine still continues to draw the attention of synthetic organic chemists and is of great scientific interest. Hence it can be concluded that many researches had investigated on thio-pyridazines having the biological activities.

\section{References}

1. Kandile NG, Mohamed MI, Zaky H, Mohamed HM (2009) Novel pyridazine derivatives: synthesis and antimicrobial activity evaluation. Eur J Med Chem 44: 1989-1996.

2. Asif M, Singh A, Ratnakar L (2011) Antimicrobial agents: brief study of pyridazine derivatives against some phathogenic microorganisms. J Pharm Res 4: 664-667.

3. Benmoussa A, El-Harti J, Ansar M (2012) Synthesis and antimicrobial properties of some pyridazin-3-thiones derivatives. Inter J Pharm Tech Res 4: 1591-1594.

4. Mangalagiu II (2011) Recent achievements in the chemistry of 1,2-diazines. Curr Org Chem 15: 730-752.

5. Mantu D, Luca MC, Moldoveanu C, Zbancioc G, Mangalagiu II (2010) Synthesis and anti-tuberculosis activity of some new pyridazine derivatives. Part II. Eur J Med Chem 45: 5164-5168.

6. Butnariu RM, Mangalagiu II (2009) New pyridazine derivatives: synthesis, chemistry and biological activity. Bioorg \& Med Chem 17: 2823-2829.

7. Drochioiu G, Sunel V, Oniscu C, Basu C, Murariu M (2001) The breakdown of plant biostructure followed by amino acids determination. Romanian Biotechnolog Lett 6: 155-165

8. Butnariu RM, Caprosu MD, Bejan V (2007) Pyridazine and phthalazine derivatives with potential antimicrobial activity. J Heterocyclic Chem 44: 11491152.

9. Dima S, Caprosu M, Ungureanu M, Grosu G, Petrovanu M (1999) Antimicrobial and antifungical activity of some new 1-methyl-phtalazinium compounds. Annales Pharmaceutiques Francaises 57: 415-416.

10. Han X, Hong YH, You Quan Z, Mao Liu Bim ZX, Fang Zhong HU, et al. (2010) Synthesis and herbicidal activities of novel 4-(3-trifluoromethylphenyl)-2Hpyridazin-3-one derivatives. Sci China Chem 53: 157-166.

11. Refaat HM, Khalil OM, Kadry HH (2007) Synthesis and anti-inflammatory activity of certain piperazinylthienylpyridazine derivatives. Archives of Pharm Res 30: 803-811

12. Liljebris C, Martinsson J, Tedenborg L, Williams M, Barker E, et al. (2002) Synthesis and biological activity of a novel class of pyridazine analogues as non-competitive reversible inhibitors of protein tyrosine phosphatase $1 \mathrm{~B}$ (PTP1B). Bioorg \& Med Chem 10: 3197-3212.

13. Tucaliuc RB, Risca IM, Drochioiu G, Mangalagiu I (2008) Biological effect of some new pyridazine derivatives on wheat in germination experiments. Romanian Biotechnolog Lett 13: 3837-3842.

14. Ishikawa T, lizawa Y, Okonogi K, Miyake A (2000) Studies on Anti-MRSA parenteral cephalosporins I. Synthesis and antibacterial activity. J Antibiotics 53: $1053-1070$.

15. Almansa C, De Arriba AF, Cavalcanti FL, Gómez LA, Miralles A, et al. (2001) Synthesis and SAR of a new series of COX-2-selective inhibitors: pyrazolo[1,5-a]pyrimidines. J Med Chem 44: 350-361. 
Citation: Asif M. (2018) A Short Review on Biological Potential Thiopyridazine Analogues. Med Chem (Los Angeles) 8: 259-264. doi: 10.4172/21610444.1000522

16. Barlin GB, Davies LP, Harrison PW (1997) Imidazo[1,2-b]pyridazines. XXI. Syntheses of some 3-acylaminomethyl-6-(chloro and iodo)-2-(substituted phenyl)imidazo[1,2-b]pyridazines and -imidazo[1,2-a]pyridines and their interaction with central and mitochondrial benzodiazepine. Aus J Chem 50: 61-68.

17. Faidallah HM, Khan KA, Makki MSI (2011) Synthesis and biological evaluation of new fused isoxazolo[4,5-d]pyridazine derivatives. J Chinese Chem Soc 58: 191-198.

18. Abd El-Ghaffar NF, Mohamed MK, Kadah MS, Radwan AM, Said GH, et al. (2011) Synthesis and antitumor activities of some new pyridazinones containing the 2-phenyl-1H-indolyl moiety. J Chem \& Pharm Res 3: 248-259.

19. Sherif MH, Ahmed GA, Elbahnasawy AA, Helal EO (2010) Chemical studies on 3,6-dichloro-pyridazine. J Am Sci 6: 570-574

20. Abd El-Salam NM, Al-Shoaibi ZY, Ahmed GA (2011) Chemical studies on 3,6-dichloro-pyridazine (Part 2). E J Chem 8: 1944-1950.

21. Abd El-Salam NM, Mostafa MS, Ahmed GA, Alothman OY (2013) Synthesis and antimicrobial activities of some new heterocyclic compounds based on 6-chloropyridazine-3(2h)-thione. J Chem.

22. Abd El-Ghaffar NF, Kadah MS, Sayed GH, Radwan AM, Abd Elal SN (2012) The use of pyridazine thione derivative in the preparation of some new heterocyclic compounds with expected antitumor activity. J Chem \& Pharm Res 4: 4562-4569.

23. Taoufiq J, Couquelet J, Paris J (1982) A convenient conversion of 3-acetyl-4aryl butanolides to 3- acetyl-4-aryl 3 butenoic acides. Synthesis 8: 660-661.

24. Chabard JL, Taoufiq J, Couquelet JD, Tranche P (1991) Comparative electron impact mass spectra and activity of new 5-Benzylidene-4.5-dihydro$(2 \mathrm{H})$-pyridazine-3-one and 4-Benzylidene-4.5-dihydrooxazi -6-one. Mass Spectrometry 26: 1082-1084.

25. Taoufiq J, Couquelet JD, Couquelet JM, Carpy A (1984) Stereo specific synthesis of 5- substituted 6-methyl 4.5-dihydropyridazin. X-ray assignment study. J Heterocyclic Chem 21: 305-310.

26. Essassi EM, Salem M (1985) Réactivité des 1,5-benzodiazépine-2-thiones. Bull Soc Chim Belg 94: 755.

27. Sotelo E, Coelho A, Raviña E (2003) Pyridazine derivatives: still-based approaches in the synthesis of 5- substituted -6-phenyl- 3(2H)-pyridazinone. Chem Pharm Bull 51: 427-430.

28. Benmoussa A, El-Harti J, Ansar M, Bouchrik M, Zahidi A, et al. (2012) Synthesis and Antimicrobial Properties of Some Pyridazin-3-Thiones Derivatives. Inter J Pharm Tech Res 4: 1591-1594.

29. Siddiqui AA, Kushnoor A, Wani SM (2004) Synthesis and hypotensive activity of some 6-(substituted aryl)-4-methyl-2,3-dihydropyridazin-3-ones. Indian J Chem 43B: 1574-1579.

30. Rubat C, Coudert P, Refouvelet B, Tronche P, Bastide P, et al. (1990) Anticonvulsant Activity of 3-Oxo-5-substituted Benzylidene-6-methyl-(4H)-2pyridazinylacetamides and 2-Pyridazinyl-acetylhydrazides. Chem Pharm Bull 38: 3009-3013.

31. Banerjee PS, Sharma PK, Nema RK (2009) Synthesis and Anticonvulsant Activity of Pyridazinone Derivatives. Inter J Chem Tech Res 1: 522-525.

32. Rathish IG, Javed K, Ahmad S, Bano S, Alam MS, et al. (2012) Synthesis and evaluation of anticancer activity of some novel 6-aryl-2 (psulfamylphenyl)pyridazin-3(2H)-ones. European Journal of Medicinal Chemistry 49: 304-309.

33. Cleeland R, Grunberg E (1985) Laboratory evaluation of new antibiotics in vitro and in experimental animal infections. Williams \& Wilkins, Baltimore, pp: 825-876.

34. Shanmugapriya M, Abdul Jameel A, Syed Ali Padusha M (2012) Synthesis, characterization and antimicrobial activities of salicylaldehyde derivatives. Int J Pharm Tech Res 4: 1.

35. Doughari JH, Pukuma MS, De N (2007) Antibacterial effects of Balanites aegyptiaca L. Drel and Moringa oleifera Lam on Salmonella typhi. Afr J Biotechnol 6: 2212-2215. 